\title{
Performance Analysis of Helical Compression spring And Banana or C Shaped Coil Spring Under Various Loading Conditions
}

\author{
Pratiksha P. Bansode* and Avinash Badadhe \\ Department of Mechanical Engineering, JSPM RSCOE SPPU, Pune, Maharashtra, INDIA
}

(Received 23 November 2020; Accepted 5 August 2021)

DOI: https://doi.org/10.36224/ijes.140303

\begin{abstract}
Suspension system is one of the major and indispensable subsystems for land vehicles and has functions of providing better road holding, handling, and ride comfort. There are many suspension system types used for automobiles, and MacPherson strut suspension is one of the most widely used suspension system type due to its favorable features like simplicity, low cost, and high performance. However, there exists a drawback of this suspension type; since the coil springs have no ability to absorb lateral forces, undesired dry friction effects on the damper may degrade the ride comfort. As remedy to this drawback, the most popular and contemporary application is the use of coil spring forms which are called side load springs.It is observed that, the vehicle drifts towards one side due to high weight of suspension system. This problem can be solved by implementation of banana-C shaped coil spring. A banana,C-shaped coil spring is designed in such a way that it, when fitted correctly, exerts an opposing force compensating for the aforementioned side load pressure. This creates a balance and leads to the best possible working conditions for the shock absorber, ensuring a longer lifetime. Creo software was utilized to design the helical compression spring. The static analysis using finite element method has been done in order to find out the detailed load vs. defection of the helical compression spring and banana-shaped coilspring.
\end{abstract}

Keywords: MacPherson Strut Suspension, Side Load Spring

\section{Introduction}

As introduced; simple structure, low cost, and compact design have led MacPherson strut suspension to become one of the most popular suspension types. Main disadvantage of the MacPherson suspension is the side force on the damper that increases friction between damper parts and resulting in degraded ride comfort. The traditional method to eliminate this drawback is to incline the spring axis with respect to the damper axis; however, the packaging size of inclined spring is limited and this solution restricts the elimination of lateral forces at the desired level. Therefore, a new spring type which is called side load spring was developed in the early 1990's. Side load springs are special type of springs which prevent the reduced ride comfort and increased wear of damper parts by generating anti sideforces.

\section{Literature review}

Gokhan Yazar[1], The traditional method to eliminate this drawback is to incline the spring axis with respect to the damper axis; however, the packaging size of inclined spring is limited and this solution restricts the elimination of lateral forces at the desired level. Therefore, a new spring type which is called side load spring was developed in the early 1990's. Side load springs are special type of springs which prevent the reduced ride comfort and increased wear of damper parts by generating anti side forces. There are certain publications about the reduction of side load on the damper in MacPherson suspension and the design and analysis procedures about the side load spring. 
H.B Pawar, D.D Desale[2], In some three wheelers the front suspension is at one side of tire. Normally, it is observed that the vehicle drifts towards one side due to high weight of front suspension system. The study is performed to reduce the weight of helical compression spring used in three-wheeler front suspension system. The objective of the present work is to optimize the front suspension system's component i.e., helical compression spring by achieving minimum of $8 \%$ to $10 \%$ reduction in weight and so incost.

\section{Problem definition/formulation}

Some of the problems that may occur to a coil spring are out of stiffness and low fatigue life. The common failure type that occurs on a spring. Failure analysis of spring is the main concern of autoparts maker and usually caused by insufficient load-carrying capacity, raw material defects, manufacturing defects and due to complex stress distribution. Therefore, specific guidelines are available for the manufacturing of coil spring type that requires fatigue stiffness and toughness to high stress.

\section{Design}

\subsection{Methodology of Design}

Part-1: In this part, not only the general information is given about the springs and also term definitions together with equations for the terms that will be used frequently in this study are given. The helical coil springs are made up of a wire coiled in the form of a helix and are intended for compressive or tensile loads. The cross-section of the wire of the spring is generally circular and the two main types of helical coil springs are compression and tension helical springs. Only the compression springs will be of interest in this study. A typical compression coilspring.

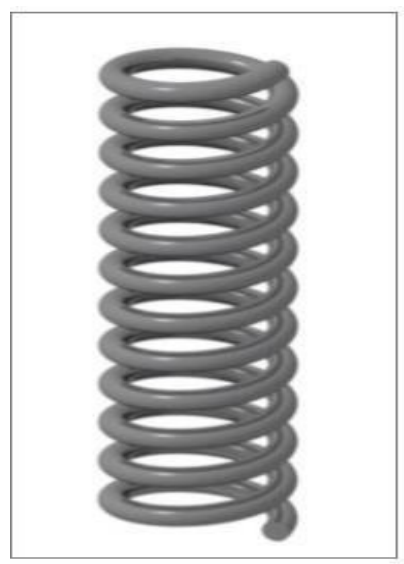

Figure 1: compression coil spring

Part II: In this section, side force problem of the MacPherson strut suspension is examined and mathematical model for spring centerline curvature is developed. As shown in figure there exists a side force FQ acting on the top of the damper rod and creates a bending moment on the damper. This side load increases the inner friction between the damper parts and results in reduced ride comfort and increased wear of the damper parts. In addition to that, vertical vibrations may be transferred to the vehicle body of vehicles with MacPherson strut suspension due to the fact that light road excitation may not be able to overcome the inner friction and this can cause to failure of operation of the suspension. In 
order to eliminate this side force, coil spring may be mounted at an inclination to the centerline of the strut. This approach, however, may not generally be possible because of space limitations. Therefore, side load springs have been used to generate lateral forces to counter sideforces.

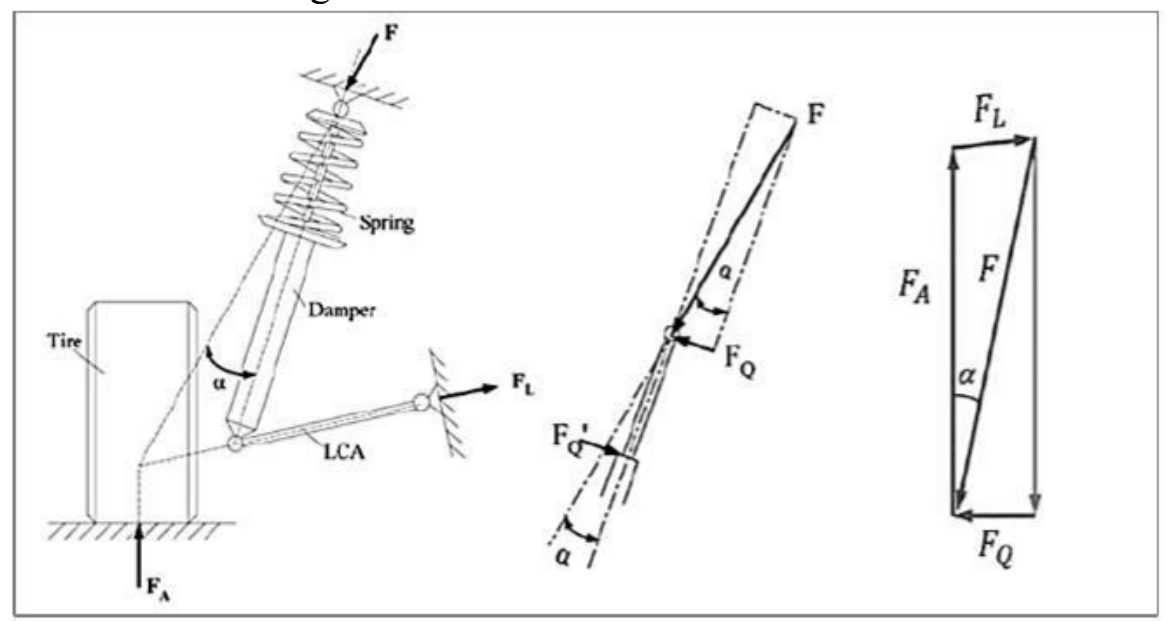

Figure 2: MacPherson strut suspension

\subsection{Design ofspring}

Diameter: $12 \mathrm{~mm}$

MeanDiameter:76mm

Freelength: $315 \mathrm{~mm}$

Number of active coils: 12

Ultimate tensile strength: $1500 \mathrm{MPa}$

$\mathrm{G}=80 \mathrm{GPa}$

$\mathrm{W}=3200 \mathrm{~N}$

Solution:
a. Spring Index
$\mathrm{C}=\underline{\mathrm{D}}$
$=76 / 12=6.33$
$d$

b. Deflection

$$
\delta=\frac{8 \mathrm{WC}^{3} \cdot \mathrm{n}}{\mathrm{Gd}} \quad=81.16 \mathrm{~mm}
$$

c. Wahl's stress factor

$$
\mathrm{K}=\frac{4 \mathrm{C}-1}{4 C-4}+\frac{0.615}{C}=\frac{4(6.33-1)}{4(6.33-4)}+\frac{0.615}{6.33}=1.23
$$

d. Maximum Shear Stress

$$
\tau=\mathrm{K} \times \frac{8 \mathrm{WC}}{\pi \mathrm{d}^{\wedge} 2}
$$$$
=4.40 \times 10^{-4}=440 \mathrm{MPA}
$$

\section{Stress Analysis}

\subsection{Loading Conditions of Springs}

As this spring is used in the Three-Wheeler Vehicle's front suspension it is necessary to find out the load acting on the spring in actual practice in static condition as well as in dynamic condition. Normally total weight of the vehicle with driver and load is about $975 \mathrm{Kg}$, concentrated at the center of gravity of the vehicle. It is assumed that this total weight is equally divided into two springs of rear 
suspension and one spring of front suspension. So the front suspension spring is experiencing load approximately $3188.25 \mathrm{~N}$ for safer side it is rounded up and taken as $3200 \mathrm{~N}$.

Shear Modulus, $\mathrm{G}=80$

GPaLoad, $\mathrm{W}=3200 \mathrm{~N}$

Poisson Ratio, $v=0.3$

\subsubsection{Case-1:Stress Analysis of Helical Spring}

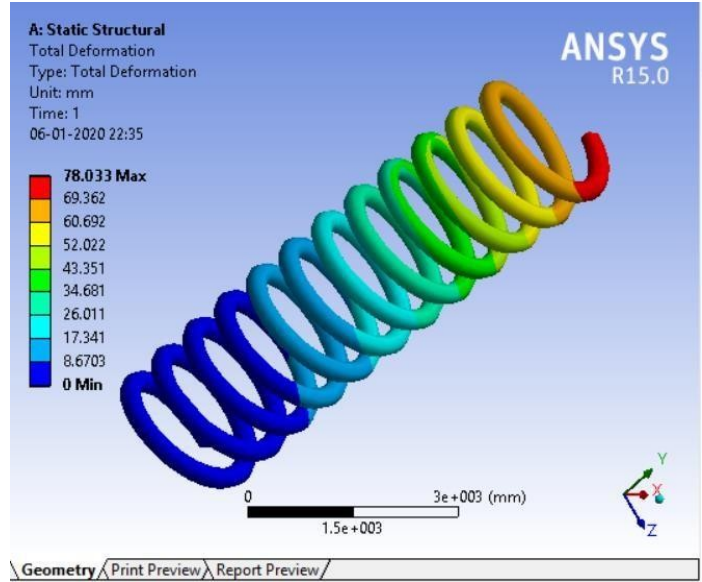

Figure 3: Total Deformation

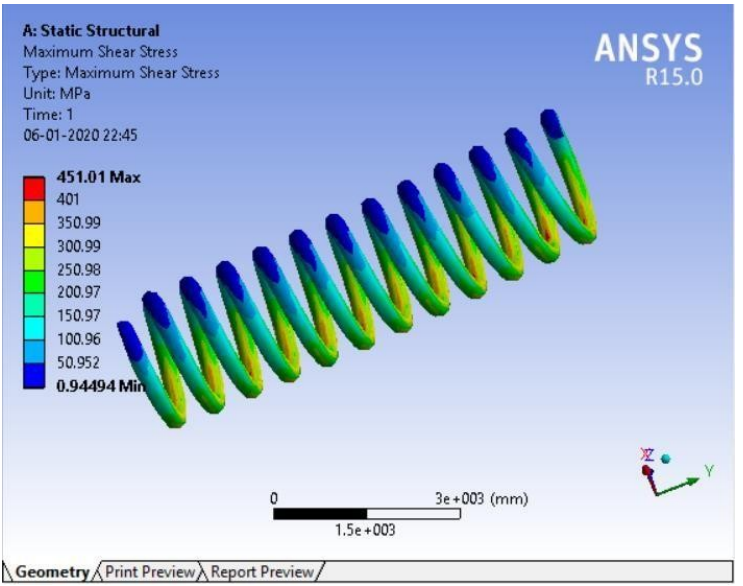

Figure 4: Maximum Shear Stress

The Total Deformation in the spring is $78.033 \mathrm{~mm}$ which is less than calculated deformation. \& The Maximum Shear Stress in the spring is $451.01 \mathrm{MPa}$

\subsubsection{Case-2: Stress Analysis of C Shaped Spring}

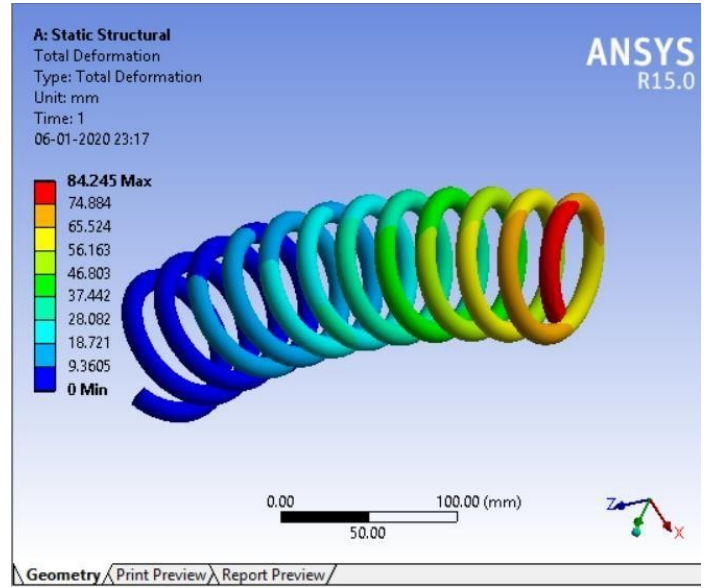

Figure 5: Total Deformation

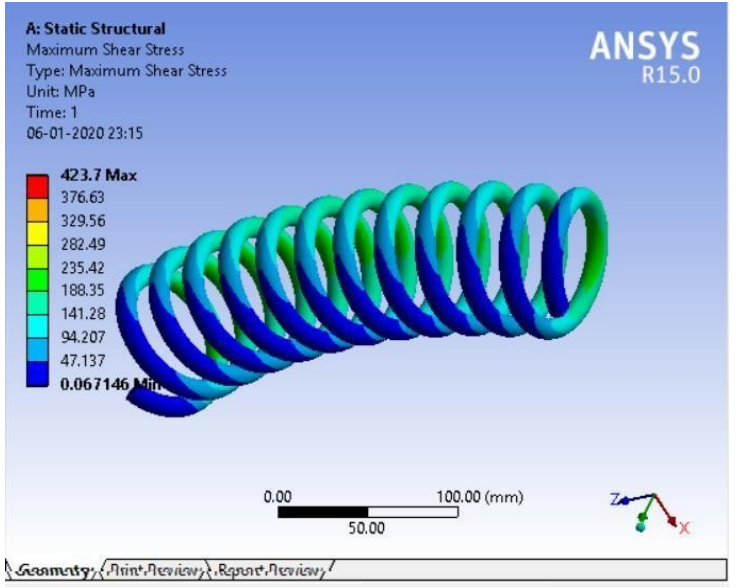

Figure 6: Maximum Shear Stress

C Shaped have Total Deformation in the spring is $84.245 \mathrm{~mm} \&$ The Maximum Shear Stress in the spring is $423.7 \mathrm{MPa}$.

\section{Results and discussion}

In this study, before starting analyses of side load spring, static analysis of a conventional helical coil spring was carried out in ANSYS to validate the analysis model with the theoretical results. While 
validating the analysis model; spring geometry, spring end connection types, and material properties were examined. After static analysis results were validated, analyses of intuitively designed side load springs were done with the same method and the results of conventional spring and side load spring were compared.

\section{Conclusion}

It is also concluded that conventional coil springs are not able to generate side force, and side force reduction in the MacPherson strut suspension is not possible by using the conventional coil springs. Since, the common application of; mounting the spring in an inclined position is not always possible due to space limitations. Therefore, using side load springs is a strong alternative to reduce side force for improving ride comfort.

\section{References}

[1] Gokhan Yazar "Design and analysis of helical coil spring forms for independent suspensions of automobiles" December2015.

[2] H.B Pawar,D.DDesale "Optimization of Three Wheeler Front Suspension Coil Spring.2351-9789,2018

[3] T. ünsche, K.-H. Muhr, K. Biecker, and L. Schnaubelt, "Side Load Springs as a Solution to Minimize Adverse Side Loads Acting on the McPherson Strut," SAE Technical Paper 940862, 1994

[4] N. Lavanya, P. S. Rao, and M. P. Reddy, "Design and Analysis of A Suspension oil Spring For Automotive Vehicle,” Int. J. Eng. Res. Appl., vol. 4, no. 9, pp. 151-157,2014 